\title{
Counterion Binding in Aqueous Solutions of Poly(vinylpyridines) as Assessed by Potentiometric Titration
}

\author{
Jim D. Roach*, Mandy M. Bondaruk, Abdulaziz Al-Abdulghani, Zaid Shahrori \\ Pre-Medical Education Unit, Weill Cornell Medicine-Qatar, Doha, Qatar \\ Email: jar2038@qatar-med.cornell.edu
}

How to cite this paper: Roach, J.D., Bondaruk, M.M., Al-Abdulghani, A. and Shahrori, Z. (2016) Counterion Binding in Aqueous Solutions of Poly(vinylpyridines) as Assessed by Potentiometric Titration. Advances in Materials Physics and Chemistry, 6, 249-261.

http://dx.doi.org/10.4236/ampc.2016.69025

Received: July 18, 2016

Accepted: September 3, 2016

Published: September 6, 2016

Copyright $\odot 2016$ by authors and Scientific Research Publishing Inc. This work is licensed under the Creative Commons Attribution International License (CC BY 4.0).

http://creativecommons.org/licenses/by/4.0/

\begin{abstract}
The extent to which counterions bind to polyelectrolytes influences a variety of polymer-based applications, including polyelectrolyte enhanced ultrafiltration and forward osmosis using polyelectrolytes as draw agents. Potentiometric titrations of poly (2-vinylpyridine) (P2VP), poly (3-vinylpyridine) (P3VP), and poly (4-vinylpydine) (P4VP) were performed using $\mathrm{HBr}, \mathrm{HCl}, \mathrm{HNO}_{3}$, and $\mathrm{HClO}_{4}$ in both the presence and absence of added $\mathrm{NaCl}$. Because of the systematic differences among the three polyelectrolytes, titration results provide insight into the role of polymer structure in the relative extents to which various counterions bind. Titration data reveal that ionization properties vary as functions of polymer investigated, titrant used, degree of protonation, and added salt concentration. Acid dissociation constants of the pyridinium moieties were found to generally increase with increasing degree of protonation, though appreciable differences were exhibited among the three polymers investigated. For all three polymers, $\mathrm{Cl}^{-}$demonstrated the lowest affinity for the charged pyridinium residues, while the affinities associated with $\mathrm{Br}^{-}$and $\mathrm{NO}_{3}^{-}$were nearly identical to each other. The relative extent of binding for $\mathrm{CIO}_{4}^{-}$varied across the polymers investigated, and was greatest for P4VP.
\end{abstract}

\section{Keywords}

Poly(vinylpyridine), Counterion Binding, Potentiometric Titration, Perchlorate

\section{Introduction}

Aqueous solutions of responsive polymers, the properties of which change according to bulk conditions, are used in a variety of colloid-based processes [1]-[4]. Of particular applicability in these processes are $\mathrm{pH}$-responsive polymers that contain acidic [5] or 
basic [6] moieties. Common polyacids include polyacrylic acid and polymethacrylic acid, while polybases include polyvinyl amine and polyethylenimine. These polymers are used in a variety of applications including drug delivery, wastewater remediation, adhesion, lubrication, and colloid stabilization. Because properties like solution density, viscosity, polymer charge density, counterion binding, and polymeric conformation are greatly influenced by the degree to which $\mathrm{pH}$-responsive polymers are protonated, their ionic equilibria are of immense interest.

The polybases poly(2-vinylpyridine) (P2VP), poly(3-vinylpyridine) (P3VP), and poly (4-vinylpyridine) (P4VP) (Figure 1), have been investigated for use in wide-ranging applications. The structures of these polyelectrolytes impart exploitable properties to materials, like membranes and gels, made from them. Investigations exploring the uses of PVP include the stabilization of non-aqueous emulsions [7] and [8] by P2VP; stimuli-responsive nanoparticles, nanogels, and capsules made using P3VP [9]; the action of colloidal silica films on nano-composites [10], the removal of perchlorate from aqueous solution [11], protonation and diffusion phenomena in weak anion-exchange membranes [12], the encapsulation of multi-walled carbon nanotubes [13], the preparation of micro porous membranes [14], and the isolation of free amino acids [15] using P4VP. The results of many of these investigations demonstrate the importance that the degree of protonation has in influencing the aqueous solution properties of PVP; properties like viscosity, swelling, and especially counterion binding.

The concept of condensation of counterions around a charged polymer was introduced by Oossawa in 1957 [16] and later expanded by Manning [17]. In his simple twostate model, Oosawa considered counterions to be either "bound" to the polyion or "unbound" in bulk aqueous solution. Affecting the extent to which counterions bind is the electrical potential of the polyion. Equation (1) represents Oosawa's relation between the apparent degree of polyion dissociation $(\beta)$, the apparent volume fraction in which bound counterions are located $(\varphi)$, and a dimensionless quantity describing the electrical potential of the polyion $(\mathrm{P})$.

$$
\ln \left(\frac{(1-\beta)}{\beta}\right)=\ln \left(\frac{\varphi}{1-\varphi}\right)+\beta \operatorname{Pln}\left(\varphi^{-1}\right)
$$

The electrical potential parameter is greatly influenced by the spacing of charged
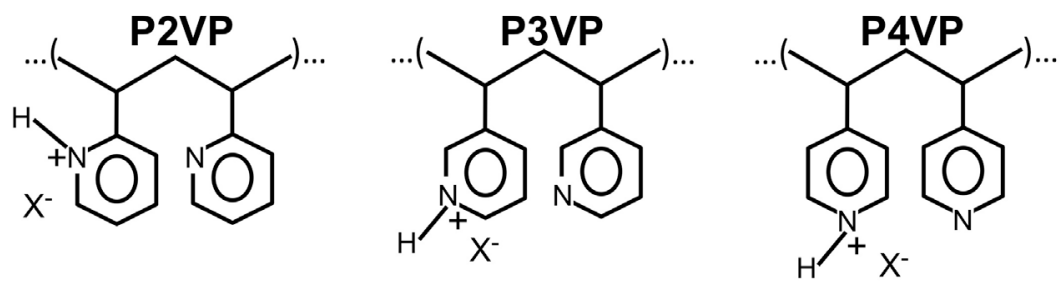

\section{where $\mathrm{X}^{-}$is $\mathrm{Br}^{-} \mathrm{Cl}^{-} \mathrm{ClO}_{4}^{-}$, or $\mathrm{NO}_{3}^{-}$}

Figure 1. Structures of poly(vinylpyridines) investigated. 
moieties along the polymer and its degree of protonation. With the spacing between charged sites increasing in the order P2VP $<$ P3VP $<$ P4VP, the titration behavior of the three PVPs provides insight into the influence of $\mathrm{P}$ and degree of protonation on counterion condensation.

Several studies have investigated the degree of protonation and other solution properties of the PVPs, beginning with Fuoss and Strauss [18]. Kirsh et al. [19] investigated $\mathrm{P} 2 \mathrm{VP}$ and P4VP in alcohol-water solutions via potentiometric titration with $\mathrm{HCl}$. Satoh et al. [20] titrated P2VP and P4VP with $\mathrm{HCl}$ and benzenesulfonic acid to assess the influence of hydrophobic interactions on counterion binding. Yoshida [21] investigated the potentiometric titration properties of $\mathrm{P} 4 \mathrm{VP}$ with $\mathrm{HCl}$ as a function of polymer molecular weight, observing that it did not influence ionization in the range $13.4 \mathrm{kDa}$ to $223 \mathrm{kDa}$. Roach et al. [11] titrated $\mathrm{P} 4 \mathrm{VP}$ with $\mathrm{HCl}$ and $\mathrm{HClO}_{4}$ in the presence and absence of added $\mathrm{NaCl}$ to assess the effect of ionic strength on the apparent polymer dissociation constant. Because the PVPs are water-soluble only at a sufficient degree of protonation, $\mathrm{pH}$ adjustment provides a mechanism whereby polymer can be recovered for reuse in applicable colloid-based processes, making PVPs potentially desirable in these applications.

In some colloid-based applications, like polyelectrolyte-enhanced ultra filtration (PEUF) processes, a higher degree of counterion binding is desired [22]; in other applications, like desalination by forward osmosis (FO) where polyelectrolytes or charged nanoparticles are used as draw agents, a lesser degree of counterion condensation leads to higher draw solution ionic strengths and greater water flux values [23]. In this study, potentiometric titrations of aqueous solutions of P2VP, P3VP, and P4VP were performed using $\mathrm{HBr}, \mathrm{HCl}, \mathrm{HNO}_{3}$, and $\mathrm{HClO}_{4}$. The apparent polymer dissociation constants were determined as functions of degree of protonation for each of the strong acids used. These data were then used to assess the relative extents to which the various counterions bind to the respective polymers.

\section{Materials and Methods}

\subsection{Chemicals}

Poly(2-vinylpyridine) with an average molecular weight of 40,000 Da and poly (4-vinylpyridine) with an average molecular weight of 50,000 Da were obtained from Polyscience Inc. Poly(3-vinylpyridine) with an average molecular weight of 50,000 Da was obtained from Apollo Scientific Limited. The molar concentrations of polymer solutions are reported in terms of their respective monomeric units. Solutions were prepared using reagent grade sodium chloride, hydrobromic acid, hydrochloric acid, nitric acid, perchloric acid, potassium hydrogen phthalate, and sodium hydroxide.

Polymer solutions were prepared by placing approximately $0.26 \mathrm{~g}$ of PVP in a $60 \mathrm{~mL}$ bottle along with an aliquot of specified strong acid, a $12 \mathrm{~mm}$ stir bar, and enough water to fill the bottle about two-thirds. The sealed mixture was stirred upright for several hours and then inverted for additional stirring until full dissolution was achieved. Finally, the contents were washed into a $100 \mathrm{~mL}$ volumetric flask. This manner of prepa- 
ration avoids clumping of polymer on the vessel walls and hastens the dissolution process.

\subsection{Potentiometric Titrations}

Solution $\mathrm{pH}$ values were determined using a Thermo Orion model 3 Star $\mathrm{pH}$ meter equipped with a 9102BNWP electrode calibrated using Gran plots created by the software GLEE [24]. The calibration provided accurate readings in the $\mathrm{pH}$ range 2.0 - 5.0. For all potentiometric titrations, the concentration of polymeric pyridine residue was approximately $0.02 \mathrm{M}$ and the initial volume of polymer solution was $30.0 \mathrm{~mL}$. Standardized strong acid titrants were approximately $0.1 \mathrm{M}$ in concentration. Aqueous polymer solutions required an initial partial protonation of between $30 \%$ and $55 \%$, depending the polymer and counter-anion being investigated. A Grant Instruments Ltd. model GP200 constant temperature water bath maintained the solutions being titrated at $25.0^{\circ} \mathrm{C} \pm 0.1^{\circ} \mathrm{C}$ throughout all experiments. Titrations were performed in triplicate and average $\mathrm{pH}$ values were used in calculating the apparent acid dissociation constants, $\mathrm{pK}_{\mathrm{a} \text {,app }}$. Standard deviations from the triplicate readings were small, equating to $<$ $0.02 \mathrm{pH}$ unit.

The acid dissociation constant $\mathrm{K}_{\mathrm{a}, \mathrm{app}}$ for protonated PVP can be expressed as in Equation (2),

$$
\mathrm{K}_{\mathrm{a}, \text { app }}=\frac{[\mathrm{P}]\left(\mathrm{a}_{\mathrm{H}}\right)}{\left[\mathrm{HP}^{+}\right]}
$$

where $[\mathrm{P}]$ and $\left[\mathrm{HP}^{+}\right]$represent the concentrations of deprotonated and protonated pyridine residues in solution, respectively, and $\mathrm{a}_{\mathrm{H}}$ is the activity of bulk proton. Taking $-\log _{10}$ of both sides provides Equation (3).

$$
\mathrm{pK}_{\mathrm{a}, \mathrm{app}}=\mathrm{pH}+\log \frac{\left[\mathrm{HP}^{+}\right]}{[\mathrm{P}]}
$$

The total concentration of pyridine residue in solution, $\mathrm{P}_{\text {tot }}$, is defined by Equation (4). The degree of

$$
\mathrm{P}_{\mathrm{tot}}=[\mathrm{P}]+\left[\mathrm{HP}^{+}\right]
$$

protonation at a given $\mathrm{pH}$ value, $\alpha$, was determined as the difference between the moles of strong acid added, $\mathrm{n}_{\mathrm{HX}}$, and that required to achieve the same $\mathrm{pH}$ in a blank sample at the same approximate ionic strength, $\mathrm{n}_{\text {blank }}$, using Equation (5).

$$
\alpha=\frac{\mathrm{n}_{\mathrm{HX}}-\mathrm{n}_{\text {blank }}}{\mathrm{P}_{\text {tot }}}
$$

Ionic strength values, I, were calculated assuming no polymeric contribution. All activity coefficients, $\gamma_{i}$, needed to relate measured activities to concentrations were calculated using the Davies equation (see Equation (6)).

$$
-\log _{10} \gamma_{i}=0.509\left(\frac{\sqrt{I}}{1+\sqrt{I}}-0.2 I\right)
$$


Combining and rearrangement of Equations (3)-(5) provides Equation (7).

$$
\mathrm{pK}_{\mathrm{a}, \mathrm{app}}=\mathrm{pH}+\log \left(\frac{\alpha}{1-\alpha}\right)
$$

Variations of $\mathrm{pK}_{\mathrm{a}, \mathrm{app}}$ with $\alpha$ have been used previously to infer polymeric conformational transitions [14] and to evaluate changes in thermodynamic parameters associated with protonation [25].

\section{Results and Discussion}

\subsection{Polymer Dissolution}

As mentioned previously, appreciable protonation of the polymers was required to achieve dissolution in water. The minimum protonation needed varied as a function of polymer and strong acid used, but was generally in the range of $30 \%-55 \%$. The range is in agreement with that reported by Satoh et al. [20] for P2VP and P4VP using HCl; by Mika and Childs [14] for P4VP using HCl; and by Roach et al. [11] for P4VP using $\mathrm{HCl}$ and $\mathrm{HClO}_{4}$. This variation is attributable to the extent to which the counter-anions bind to cationic sites on the polymeric strand. A greater level of binding requires a higher degree of protonation to achieve dissolution. From each titration performed, the $\mathrm{pK}_{\mathrm{a}, \mathrm{app}}$ at $\alpha=0.55, \mathrm{pK}_{\mathrm{a}, \mathrm{app}(0.55)}$, was determined and used to compare behavior across the polymers and acids studied; 55\% protonation is the lower limit of solubility for P3VP and $\mathrm{P} 4 \mathrm{VP}$ with $\mathrm{CIO}_{4}^{-}$counterions. A similar technique was employed previously by Yoshida [21] when assessing the aqueous solution properties of P4VP with $\mathrm{HCl}$.

\subsection{Polymer Titrations in the Absence of Added Salt}

The dependences of $\mathrm{pK}_{\mathrm{a}, \text { app }}$ on $\alpha$ for P2VP, P3VP, and P4VP, in the absence of added salt, are depicted in Figures 2-4. For all three polymers with all four strong acids studied,

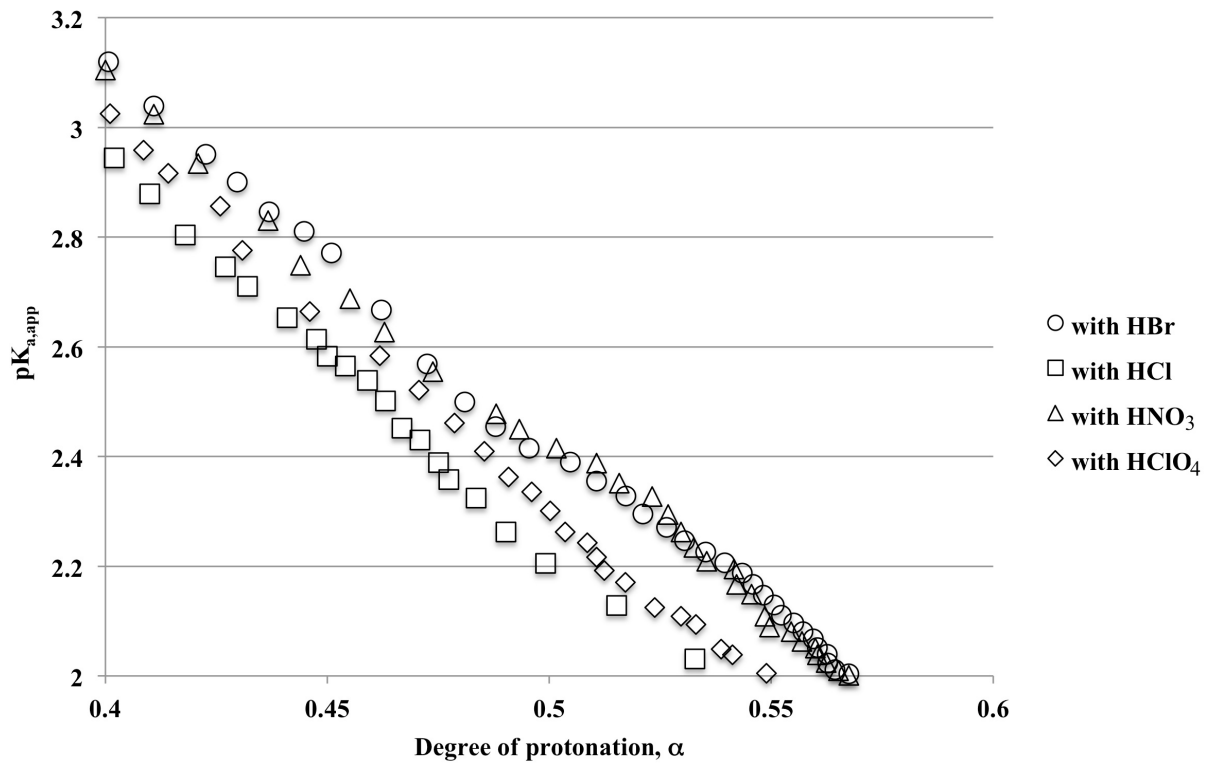

Figure 2. Titrations of $\mathrm{P} 2 \mathrm{VP}$ at $25^{\circ} \mathrm{C}$ with no added salt. 


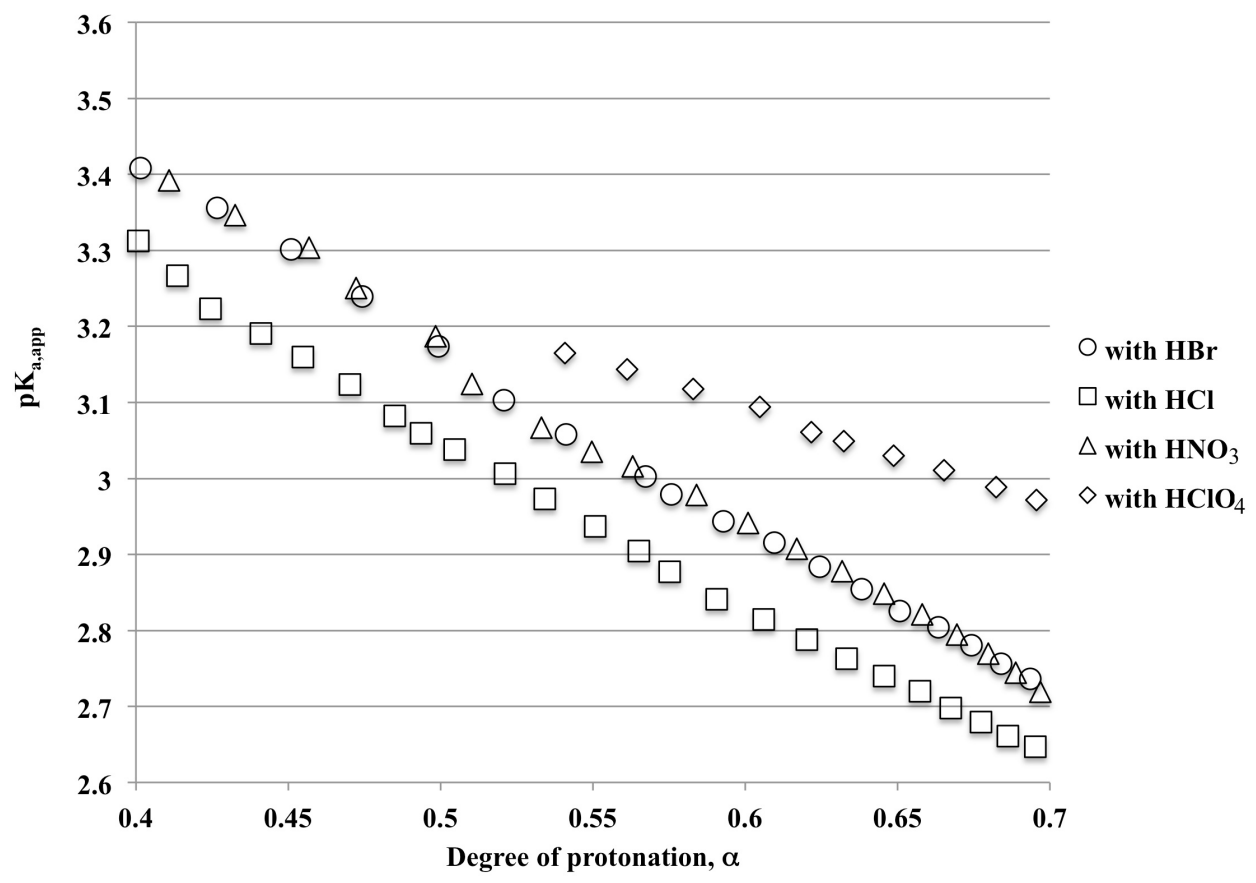

Figure 3. Titrations of P3VP at $25^{\circ} \mathrm{C}$ with no added salt.

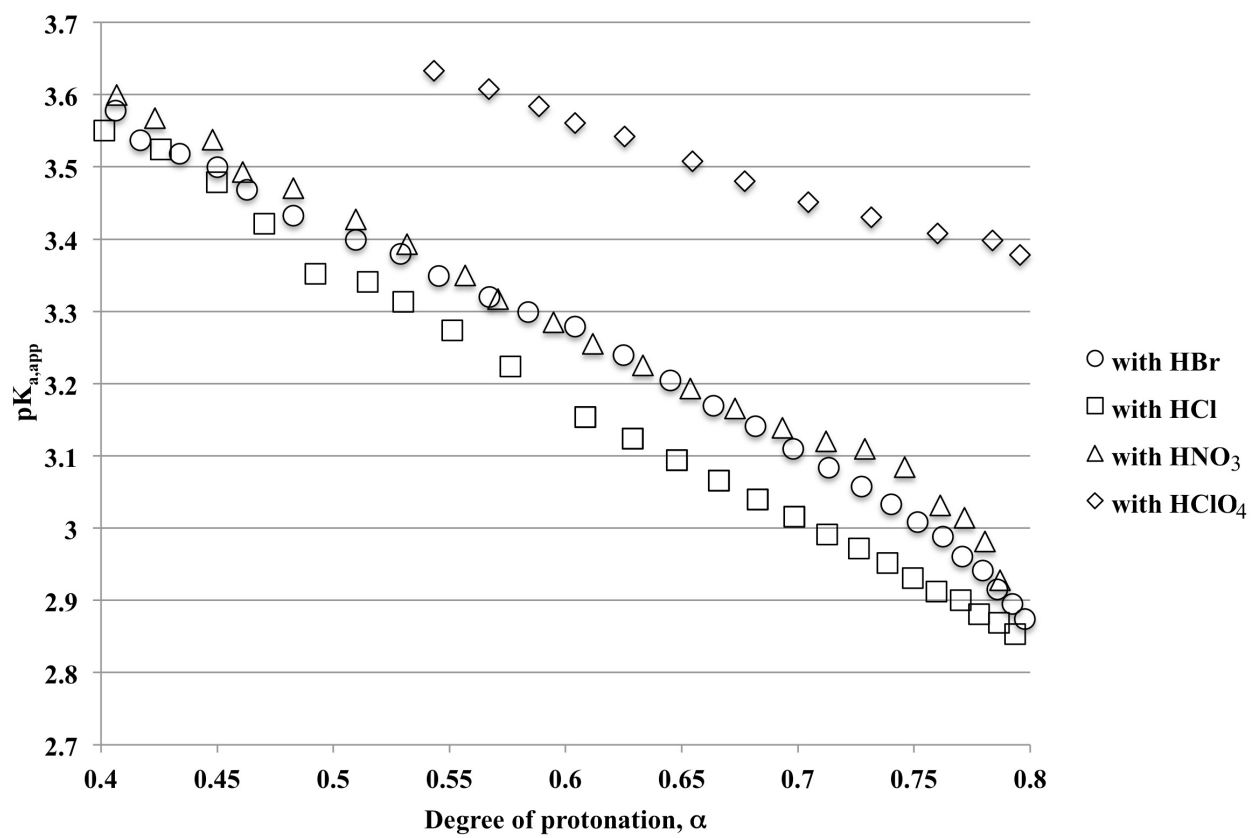

Figure 4. Titrations of $\mathrm{P} 4 \mathrm{VP}$ at $25^{\circ} \mathrm{C}$ with no added salt.

$\mathrm{pK}_{\mathrm{a}, \text { app }}$ is observed to decrease with increasing $\alpha$ in the range $\alpha=0.4-0.8$. This trend is attributable to the increasingly cationic character of the solvated polymer at higher $\alpha$ values. Protonated pyridine residues repulse hydronium, thus hindering their acquisition by neighboring residues and increasing the observed acid dissociation constant. While the general trend is deceasing $\mathrm{pK}_{\mathrm{a}, \text { app }}$ with increasing $\alpha$, the slopes vary across the three polymers investigated. This variation can be evaluated by incorporation of a factor, 
$\mathrm{q}$, into an expression similar to Equation (7), except $\mathrm{pK}_{\mathrm{a}}$ is now the intercept of $\mathrm{pH}$ vs. $\log \left(\frac{1-\alpha}{\alpha}\right)$.

$$
p H=\mathrm{pK}_{\mathrm{a}}+\mathrm{q} \times \log \left(\frac{1-\alpha}{\alpha}\right)
$$

Values for parameter $\mathrm{q}$ were obtained from plots of $\mathrm{pH}$ vs. $\log \left(\frac{1-\alpha}{\alpha}\right)$ and are summarized in Table 1. Parameter $\mathrm{q}$ is generally greater than 1 and is observed to increase in the order P4VP $<$ P3VP $<\mathrm{P} 2 \mathrm{VP}$. This trend is likely due to varying electrostatic interactions along the respective polymeric chains, which hinder protonation of neighboring pyridine residues to differing extents; larger $\mathrm{q}$ values indicating greater repulsion. NMR studies conducted by Emsly [26] on pyridinium revealed that greater than $70 \%$ of positive charges are delocalized across the protons, $\alpha$ carbons, and their $\alpha$ hydrogens. Because these moieties are closer on P2VP than on P3VP, which in turn are closer than those on P4VP, repulsive interactions are greatest within P2VP and are least prominent within P4VP. In their studies of P2VP and P4VP, Satoh et al. [20] observed that $\mathrm{P} 2 \mathrm{VP}$ solutions had higher viscosities than $\mathrm{P} 4 \mathrm{VP}$ at a given $\alpha$ value, suggesting that P2VP adopts a more elongated conformation because of increased repulsion between charged sites. The q value of 1.0 obtained from titrations of $\mathrm{P} 4 \mathrm{VP}$ with $\mathrm{HClO}_{4}$ indicate extensive counterion binding, thus significantly reducing repulsion between neighboring pyridinium residues; $\mathrm{CIO}_{4}^{-}$provides a high shielding effect within P4VP.

Differences in $\mathrm{pK}_{\mathrm{a}, \text { app }}$ at a given $\alpha$, for a given polymer, are attributed to the varying extents to which the strong acid anions bind to protonated pyridine residues. Higher degrees of counterion condensation reduce the effective charge on the polycation, thus providing greater $\mathrm{pK}_{\mathrm{a}, \mathrm{app}}$ values. These differences are exploited to assess the relative

Table 1. Values of $\mathrm{q}$ and $\mathrm{pK}$ a,app(0.55) for P2VP, P3VP, and P4VP titrations using $\mathrm{HBr}, \mathrm{HCl}, \mathrm{HNO}_{3}$, and $\mathrm{HClO}_{4}$ at $25^{\circ} \mathrm{C}$ with no added salt.

\begin{tabular}{cccc}
\hline Polymer & Titrant & $\mathrm{q}$ & $\mathrm{pK}_{\text {a,app(0.55) }}$ \\
\hline P2VP & $\mathrm{HBr}$ & 4.1 & 2.13 \\
& $\mathrm{HCl}$ & 4.2 & 1.86 \\
& $\mathrm{HNO}_{3}$ & 4.0 & 2.09 \\
& $\mathrm{HClO}_{4}$ & 4.1 & 2.00 \\
$\mathrm{P3VP}$ & $\mathrm{HBr}$ & 1.9 & 3.03 \\
& $\mathrm{HCl}$ & 2.1 & 2.92 \\
& $\mathrm{HNO}_{3}$ & 1.9 & 3.03 \\
& $\mathrm{HClO}_{4}$ & 1.3 & 3.15 \\
& $\mathrm{HBr}^{\mathrm{P}}$ & 1.5 & 3.34 \\
& $\mathrm{HCl}$ & 1.8 & 3.27 \\
& $\mathrm{HNO}_{3}$ & 1.5 & 3.36 \\
& $\mathrm{HClO}_{4}$ & 1.0 & 3.62 \\
\hline
\end{tabular}


extents to which $\mathrm{Br}^{-}, \mathrm{Cl}^{-}, \mathrm{NO}_{3}^{-}$, and $\mathrm{CIO}_{4}^{-}$bind to the PVPs. Ochiai et al. used potentiometric titration results in a similar way to assess the dissociation behavior of various poly(allylammonium) salts [27] and Lewis et al. did the same for poly(vinylammonium) salts [25]. In the present work, from titrations of $\mathrm{P} 2 \mathrm{VP}, \mathrm{Cl}^{-}$is observed to have the lowest shielding effect while $\mathrm{Br}^{-}$and $\mathrm{NO}_{3}^{-}$displayed very similar binding properties. For P3VP and $\mathrm{P} 4 \mathrm{VP}$, the degree of counterion binding is observed to increase in the order $\mathrm{Cl}^{-}<\mathrm{Br}^{-} \approx \mathrm{NO}_{3}^{-}<\mathrm{CIO}_{4}^{-}$, with the displacement of $\mathrm{CIO}_{4}^{-} \mathrm{pK}_{\mathrm{a}, \text { app }}$ values being particularly pronounced with $\mathrm{P} 4 \mathrm{VP}$.

For all three polymers, $\mathrm{Cl}^{-}$is observed to the have the lowest shielding effect. As data in Table 2 indicate, $\mathrm{Cl}^{-}$has the smallest thermo chemical radius and largest free energy of dehydration among the anions investigated. It is also the most stabilizing anion of the four within the Hofmeister series [28]. In terms of a pseudo phase model, one could argue that its high dehydration energy imparts less partitioning of $\mathrm{Cl}^{-}$into the polyelectrolyte pseudo phase and, therefore, less effective shielding of the polymer's cationic character.

Both $\mathrm{Br}^{-}$and $\mathrm{NO}_{3}^{-}$are observed to provide essentially the same extent of counterion binding at a given $\alpha$ for all three polymers. Although $\mathrm{NO}_{3}^{-}$has a slightly larger thermo chemical radius, its free energy of dehydration is slightly less than that of $\mathrm{Br}^{-}$. These competing effects are perhaps compensatory and provide for similar counterion binding results with PVPs. Within various expressions of the Hofmeister series, $\mathrm{Br}^{-}$and $\mathrm{NO}_{3}^{-}$are often equated [29]. In ion chromatography, which involves similar counterion-polyelectrolyte interactions, $\mathrm{Br}^{-}$and $\mathrm{NO}_{3}^{-}$are notoriously difficult to separate on ion exchange columns, as they tend to exhibit very similar binding behaviors [30]. The results of the present work seem to indicate that resins derivatized with PVPs would not serve well in chromatographic or ion-exchange applications involving $\mathrm{Br}^{-}$and $\mathrm{NO}_{3}^{-}$.

The titration results for $\mathrm{CIO}_{4}^{-}$are intriguing. Its effectiveness as a shielding agent, relative to the other anions studied, increases in the order P2VP $<$ P3VP $<$ P4VP. With a relatively large thermo chemical radius and correspondingly small free energy of dehydration, $\mathrm{CIO}_{4}^{-}$might be expected to partition well into cationic polyelectrolyte pseudophases. This partitioning has been exploited as a removal strategy in PEUF using poly(diallyldimethyl ammonium) chloride [22] and [31]. When studied as a precipitating agent with poly (1,2 dimethyl-5-vinylpyridinium chloride), $\mathrm{CIO}_{4}^{-}$was found to perform best when compared to $\mathrm{Br}^{-}, \mathrm{Cl}^{-}$, and $\mathrm{NO}_{3}^{-}$, indicating strong affinity for the

Table 2. Physical constants of poly(vinylpyridines) and selected anions [34]-[36].

\begin{tabular}{cccccc}
\hline Polymer & $\mathrm{pK}_{0}$ in $0.1 \mathrm{M} \mathrm{NaCl}$ & Anion & $\begin{array}{c}\text { Thermo chemical } \\
\text { Radius (nm) }\end{array}$ & $\begin{array}{c}\text { Free energy of } \\
\text { hydration }(\mathrm{kJ} / \mathrm{mol})\end{array}$ & $\begin{array}{c}\text { Electron } \\
\text { donor }\end{array}$ \\
\hline P2VP & $5.1 \pm 0.2$ & $\mathrm{Br}^{-}$ & 0.188 & -315 & 1.51 \\
P3VP & $5.2 \pm 0.2$ & $\mathrm{Cl}^{-}$ & 0.172 & -340 & 1.24 \\
P4VP & $5.1 \pm 0.2$ & $\mathrm{NO}_{3}^{-}$ & 0.196 & -300 & 0.29 \\
& & $\mathrm{CIO}_{4}^{-}$ & 0.240 & -205 & -0.73 \\
\hline
\end{tabular}


quaternized moieties [29]. In addition, in their studies of poly (allylammonium) with various counterions, Ochiai et al. [27] also observed that $\mathrm{CIO}_{4}^{-}$was the most effective shielding agent among the anions studied. However, Lewis et al. [25] found that shielding decreased in the order $\mathrm{Cl}^{-}>\mathrm{Br}^{-}>\mathrm{I}^{-}>\mathrm{CIO}_{4}^{-}$for poly (vinyl ammonium) salts. Similarly, Cook and Riley [32] found that P2VP micro gels demonstrate greater affinity for $\mathrm{Cl}^{-}$than $\mathrm{CIO}_{4}^{-}$in the range $\alpha=0.4-0.6$. Clearly many factors, both polymeric and counter ionic, influence binding behavior, necessitating experimental assessment using a method like potentiometric titration.

Several parameters have been suggested to correlate the extent to which various anions bind to cationic polyelectrolytes, some of which are provided in Table 2. Thermochemical radius and dehydration energies are commonly used in explaining binding phenomena. The results of Ochiai et al. [27] correlate well with the electron donor constant, $E_{n}$, an empirical parameter representing an anions hardness and polarizability. Burkhardt et al. [29] suggest using ionic polarizability values, but their results correlate poorly with $\mathrm{CIO}_{4}^{-}$. The addition of a single methylene spacer, in going from poly (vinylammonium) to poly (allylammonium), leads to markedly different binding results [25] and [27]. In much the same way the present study demonstrates the position of the nitrogen atom in relation to the polymeric backbone greatly influences the relative extents to which anions bind to PVPs. Interestingly, $\mathrm{CIO}_{4}^{-}$shows greater affinity for poly (allylammonium) when compared to poly (vinyl ammonium) and for P4VP when compared to P3VP and P2VP. Increasing the distance of the charged moiety from the polymeric alkyl chain seems to enhance $\mathrm{CIO}_{4}^{-}$binding efficiency, perhaps the result of steric hindrances.

\subsection{Polymer Titrations in the Presence of Added Salt}

Table 2 also provides values for the intrinsic acid dissociation constants in the absence of neighboring electrostatic interactions, $\mathrm{pK}_{0}$, which were linearly extrapolated as the value of $\mathrm{pK}_{\mathrm{a} \text {,app }}$ at $\alpha=0$ in $0.10 \mathrm{M} \mathrm{NaCl}$. Previous studies provided $\mathrm{pK}_{0}$ values for the monomer analogs 2-ethylpyridine and 4-ethylpyridine in $0.1 \mathrm{M} \mathrm{NaCl}$, which are 6.04 and 6.14, respectively [20]. These values are considerably higher than those extrapolated for pyridine residues on the polymers studied. Kirsh et al. [33] attribute the decreases in $\mathrm{pK}_{0}$ values in polymers to lower effective dielectric constants associated with the local environment in the vicinity of the polymer backbone; the pyridine residue preferring to remain uncharged when in a medium of lower dielectric constant. However, no differences in $\mathrm{pK}_{0}$ were observed among the three polymers in $0.1 \mathrm{M} \mathrm{NaCl}$ despite the position of the nitrogen moving relative to the alkyl chain. This is likely a result of the mitigating influence of the added salt. Marked changes in ionic strength at low and high degrees of protonation prevent meaningful extrapolations of $\mathrm{pK}_{0}$ in the absence of added salt.

Figure 5 demonstrates the effect of added $\mathrm{NaCl}$ on the titration behavior of PVPs with $\mathrm{HCl}$. The $\mathrm{pK}_{\mathrm{a}, \mathrm{app}}$ values for all polymers increase across the $\alpha$ range investigated in the presence of $\mathrm{NaCl}$, further illustrating that there are strong electrostatic repulsive forces between both neighboring pyridinium residues, and between those residues and 


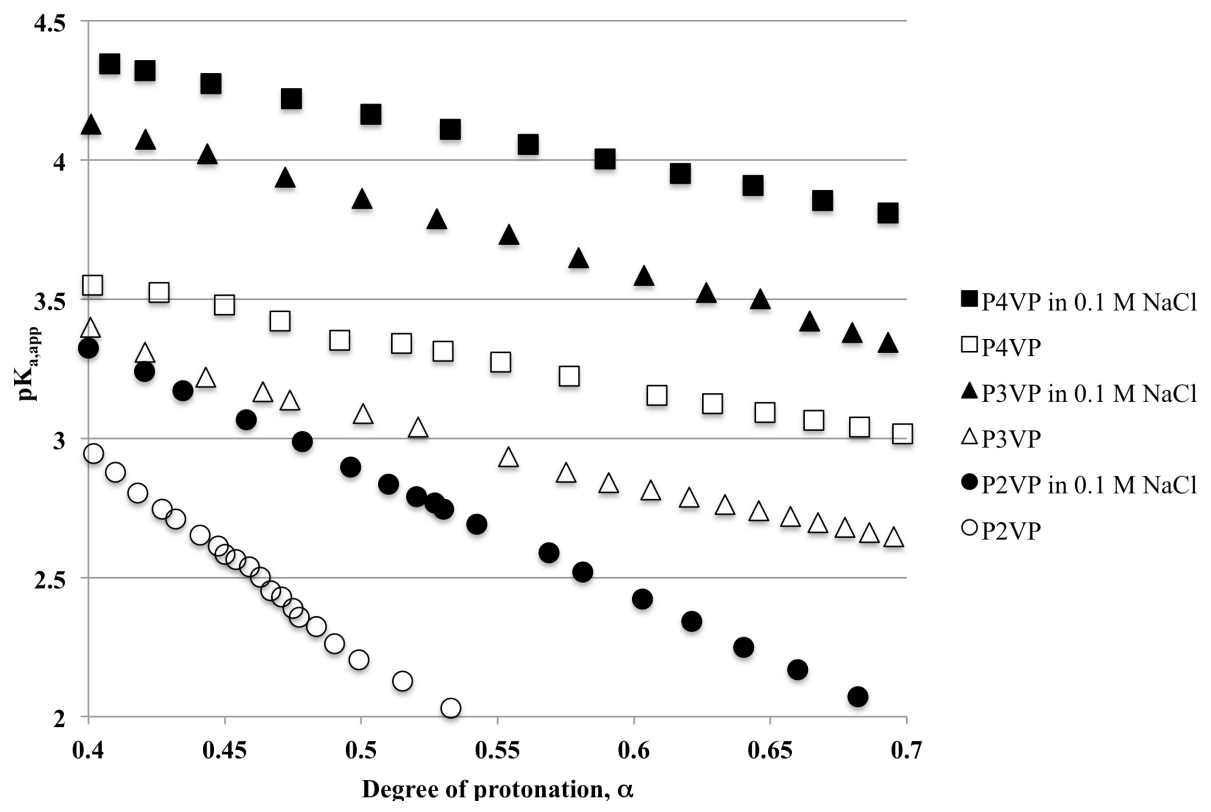

Figure 5. Titrations of $\mathrm{P} 2 \mathrm{VP}, \mathrm{P} 3 \mathrm{VP}$, and $\mathrm{P} 4 \mathrm{VP}$ with $\mathrm{HCl}$ in the presence and absence of $\mathrm{NaCl}$.

hydronium. The addition of competing $\mathrm{Cl}^{-}$counterions serves to reduce this repulsion, thus enhancing the ease with which the pyridine moieties are protonated and increasing $\mathrm{pK}_{\mathrm{a}, \mathrm{app}}$. Because of water's high dielectric constant, these results are best explained in terms of electrostatic interactions taking place through the polymer as opposed to through the solution. Viscosity measurements of P2VP and P4VP solutions by Kirsh et al. [19] further illustrate this mechanism of interaction.

\section{Conclusion}

Potentiometric titrations have been used to investigate various aspects of the interactions of $\mathrm{Br}^{-}, \mathrm{Cl}^{-}, \mathrm{NO}_{3}^{-}$, and $\mathrm{CIO}_{4}^{-}$with $\mathrm{P} 2 \mathrm{VP}, \mathrm{P} 3 \mathrm{VP}$, and P4VP. For all three polymers, $\mathrm{Cl}^{-}$demonstrated the lowest relative affinity for the pyrdinium residues, while the affinities associated with $\mathrm{Br}^{-}$and $\mathrm{NO}_{3}^{-}$were nearly identical to each other. The relative extent of binding for $\mathrm{CIO}_{4}^{-}$varied across the polymers investigated, and was greatest for P4VP. Slight differences in the position of the pyridinium residues greatly affect the relative binding of counter-anions to $\mathrm{P} 2 \mathrm{VP}, \mathrm{P} 3 \mathrm{VP}$, and $\mathrm{P} 4 \mathrm{VP}$, especially for $\mathrm{CIO}_{4}^{-}$. In addition, very similar values for the intrinsic acid dissociation constants, $\mathrm{pK}_{0}$, were obtained for all three polymers. These results demonstrate that no single, simple theory or parameter adequately predict polyelectrolyte-counterion binding behavior. Potentiometric titrations, in the absence of added salt, provide a convenient method of assessing relative binding affinity.

\section{References}

[1] Chen, J. and Chang, C. (2014) Fabrications and Applications of Stimulus-Responsive Polymer Films and Patterns on Surfaces: A Review. Materials, 7, 805-875.

http://dx.doi.org/10.3390/ma7020805 
[2] Cabane, E., Zhang, X., Langowska, K., Palivan, C. and Meier, W. (2012) Stimuli-Responsive Polymer and Their Applications in Nanomedicine. Biointerphases, 7, 9-36. http://dx.doi.org/10.1007/s13758-011-0009-3

[3] Stuart, M.A.C., Huck, W.T., Genzer, J., Muller, M., Ober, C., Stamm, M., Sukhorukow, G.B., Szleifer, I., Tsukruk, V.V., Urban, M., Winnik, F., Zauscher, S., Luzinov, I. and Minko, S. (2010) Emerging Applications of Stimuli-Responsive Polymer Materials. Nature Materials, 9, 101-113. http://dx.doi.org/10.1038/nmat2614

[4] Bajpai, A.K., Shukla, S.K., Bhanu, S. and Kankane, S. (2008) Responsive Polymers in Controlled Drug Delivery. Progress in Polymer Science, 33, 1088-1118. http://dx.doi.org/10.1016/j.progpolymsci.2008.07.005

[5] Schmaljohann, D. (2006) Thermo- and pH-Responsive Polymer in Drug Delivery. Advanced Drug Delivery Reviews, 58, 1655-1670. http://dx.doi.org/10.1016/j.addr.2006.09.020

[6] Sanjuan, S., Perrin, P., Pantoustier, N. and Tran, Y. (2007) Synthesis and Swelling Behavior of pH-Responsive Polybase Brushes. Langmuir, 23, 5769-5778. http://dx.doi.org/10.1021/la063450z

[7] Atanase, L.I. and Riess, G. (2014) Stabilization of Non-Aqueous Emulsions by Poly (2-vinylpyridine)-b-Poly(butadiene) Block Copolymers. Colloids and Surfaces A: Physiochemical and Engineering Aspects, 458, 19-24. http://dx.doi.org/10.1016/j.colsurfa.2014.01.026

[8] Atanase, L.I., Lerch, J.P. and Riess, G. (2015) Water Dispersibility of Non-Aqueous Emulsions Stabilized and Viscosified by Poly(butadiene)-Poly(2-vinylpyridine)-Poly(ethylene oxide) (PBut-P2VP-PEO) Triblock Copolymer. Colloids and Surfaces A: Physiochemical and Engineering Aspects, 464, 89-95. http://dx.doi.org/10.1016/j.colsurfa.2014.10.026

[9] Motornov, M., Roiter, Y., Tokarev, I. and Minko, S. (2010) Stimuli-Responsive Nanoparticles, Nanogels and Capsules for Integrated Multifunctional Intelligent Systems. Progress in Polymer Science, 35, 174-211. http://dx.doi.org/10.1016/j.progpolymsci.2009.10.004

[10] Abdalla, S., Al-Marzouki, F., Obaid, A. and Gamal, S. (2016) Action of Colloidal Silica Films on Different Nano-Composites. Results in Physics, 6, 209-214.

http://dx.doi.org/10.1016/j.rinp.2016.04.014

[11] Roach, J.D., Lane, R.L. and Hussain, Y. (2011) Comparative Study of the Uses of Poly (4-vinylpyridine) and Poly(diallyldimethylammonium) Chloride for the Removal of Perchlorate from Aqueous Solution by Polyelectrolyte-Enhanced Ultrafiltration. Water Research, 45, 1387-1393. http://dx.doi.org/10.1016/j.watres.2010.10.027

[12] Frank-Lacaze, L., Sistat, P., Huguet, P. and Lapicque, F. (2009) Protonation and Diffusion Phenomena in Poly(4-vinylpyridine)-Based Weak Anion-Exchange Membranes. Journal of Membrane Science, 340, 257-265. http://dx.doi.org/10.1016/j.memsci.2009.05.046

[13] Hong, S., Kim, M., Hong, C.K., Jung, D. and Shim, S.E. (2008) Encapsulation of MultiWalled Carbon Nanotubes by Poly(4-vinylpyridine) and Its Dispersion in Various Solvent Media. Synthetic Metals, 158, 900-907. http://dx.doi.org/10.1016/j.synthmet.2008.06.023

[14] Mika, A.M. and Childs, R.F. (1999) Acid/Base Properties of Poly(4-vinylpyridine) Anchored within Microporous Membranes. Journal of Membrane Science, 152, 129-140. http://dx.doi.org/10.1016/S0376-7388(98)00219-1

[15] Jewett, D.M. and Ehrenkaufer, R.L. (1982) Rapid and Efficient Preparation of Free Amino Acids from Strong Acid Salts on Columns of Crosslinked Poly(4-vinylpyridine). Analytical Biochemistry, 122, 319-321. http://dx.doi.org/10.1016/0003-2697(82)90289-5

[16] Oosawa, F. (1957) A Simple Theory of Thermodynamic Properties of Polyelectrolyte Solutions. Journal of Polymer Science Part A: Polymer Chemistry, 23, 421-430.

http://dx.doi.org/10.1002/pol.1957.1202310335 
[17] Manning, G.S. (1969) Limiting Laws and Counterion Condensation in Polyelectrolyte Solutions. The Journal of Chemical Physics, 51, 924-933. http://dx.doi.org/10.1063/1.1672157

[18] Fuoss, R.M. and Strauss, U.P. (1948) Polyelectrolytes. II. Poly-4-vinylpyridonium Chloride and Poly-4-vinyl- $N$ - $n$-butylpyridonium Bromide. Journal of Polymer Science Part A: Polymer Chemistry, 3, 246-263. http://dx.doi.org/10.1002/pol.1948.120030211

[19] Kirsh, Y.E., Komarova, O.P. and Lukovkin, G.M. (1973) Physico-Chemical Study of Ionic Equilibria for Poly-2 and Poly-4-vinylpyridines in Alcohol-Water Solutions. European Polymer Journal, 9, 1405-1415. http://dx.doi.org/10.1016/0014-3057(73)90110-9

[20] Satoh, M., Yoda, E., Hayashi, T. and Komiyama, J. (1989) Potentiometric Titration of Poly(vinylpyridines) and Hydrophobic Interaction in the Counterion Binding. Macromolecules, 22, 1808-1812. http://dx.doi.org/10.1021/ma00194a051

[21] Yoshida, M. (1997) Solution Properties of Polyvinylpyridine in Acid-II. Solution Properties of Poly(4-vinylpyridine) in Aqueous Solution of Hydrochloric Acid. European Polymer Journal, 33, 943-948. http://dx.doi.org/10.1016/S0014-3057(96)00140-1

[22] Roach, J.D. and Tush, D. (2008) Equilibrium Dialysis and Ultrafiltration Investigations of Perchlorate Removal from Aqueous Solution Using Poly(diallyldimethylammonium) Chloride. Water Research, 42, 1204-1210. http://dx.doi.org/10.1016/j.watres.2007.09.003

[23] Ge, Q., Su, J., Amy, G.L. and Chung, T. (2012) Exploration of Polyelectrolytes as Draw Solutes in Forward Osmosis Processes. Water Research, 46, 1318-1326. http://dx.doi.org/10.1016/j.watres.2011.12.043

[24] Gans, P. and O’Sullivan, B. (2000) GLEE, a New Computer Program for Glass Electrode Calibration. Talanta, 51, 33-37. http://dx.doi.org/10.1016/S0039-9140(99)00245-3

[25] Lewis, E.A., Barkley, T.J., Reams, R.R. and Hansen, L.D. (1984) Thermodynamics of Proton Ionization from Poly(vinylammonium Salts). Macromolecules, 17, 2874-2881. http://dx.doi.org/10.1021/ma00142a073

[26] Emsley, J.W. (1968) A Semi-Empirical Self Consistent Field Molecular Orbital Calculation on Pyridine and Pyridinium Ion Including All Valence Electrons. Journal of Chemical Society A: Inorganic, Physical, Theoretical, 1387-1393.

http://dx.doi.org/10.1039/j19680001387

[27] Ochiai, H., Anabuki, Y., Kojima, O., Tominaga, K. and Murakami, I. (1990) Dissociation of Poly(allylammonium) Cations in Salt Solutions. Journal of Polymer Science: Part B: Polymer Physics, 28, 233-240. http://dx.doi.org/10.1002/polb.1990.090280209

[28] Salis, A. and Ninham, B.W. (2014) Models and Mechanisms of Hofmeister Effects in Electrolyte Solutions, and Colloid and Protein Systems Revisited. Chemical Society Reviews, 43, 7358-7377. http://dx.doi.org/10.1039/C4CS00144C

[29] Burkhardt, C.W., Parazak, D.P., McCarthy, K.J. and Jackson, G.J. (1986) Specific Counterion Binding to Cationic Polyelectrolytes. Journal of Applied Polymer Science, 32, 47014708. http://dx.doi.org/10.1002/app.1986.070320434

[30] Tirumalesh, K. (2008) Simultaneous Determination of Bromide and Nitrate in Contaminated Waters by Ion Chromatography Using Amperometry and Absorbance Detectors. Talanta, 74, 1428-1434. http://dx.doi.org/10.1016/j.talanta.2007.09.021

[31] Huq, H.P., Yang, J.S. and Yang, J.W. (2007) Removal of Perchlorate from Groundwater by the Polyelectrolyte-Enhanced Ultrafiltration Process. Desalination, 204, 335-343. http://dx.doi.org/10.1016/j.desal.2006.02.039

[32] Cook, J.P. and Riley, D.J. (2009) The Effect of Perchlorate Ions on a Pyridine-Based Microgel. Advances in Colloid and Interface Science, 147, 67-73. http://dx.doi.org/10.1016/j.cis.2008.11.002 
[33] Kirsh, Y.E. (1985) Reactivity and Physico-Chemical Properties of Nitrogen-Containing Carbon-Chain Polymers in Aqueous Solutions. Progress in Polymer Science, 11, 283-338. http://dx.doi.org/10.1016/0079-6700(85)90010-3

[34] Moyer, B. and Bonnesen, P.V. (1979) Physical Factors in Anion Separation. In: Bianchi, A., Bowman-James, K. and Garcia-Espana, E., Eds., Supramolecular Chemistry of Anions, Wiley-VCH, Inc., New York, 1-44.

[35] Yamada, S. and Tanaka, M. (1975) Softness of Some Metal Ions. Journal of Inorganic and Nuclear Chemistry, 37, 587-589. http://dx.doi.org/10.1016/0022-1902(75)80387-3

[36] Edwards, J.O. (1956) Polarizability, Basicity and Nuleophilic Character. Journal of the American Chemical Society, 78, 1819-1820. http://dx.doi.org/10.1021/ja01590a012

\section{Submit or recommend next manuscript to SCIRP and we will provide best service} for you:

Accepting pre-submission inquiries through Email, Facebook, LinkedIn, Twitter, etc. A wide selection of journals (inclusive of 9 subjects, more than 200 journals)

Providing 24-hour high-quality service

User-friendly online submission system

Fair and swift peer-review system

Efficient typesetting and proofreading procedure

Display of the result of downloads and visits, as well as the number of cited articles Maximum dissemination of your research work

Submit your manuscript at: http://papersubmission.scirp.org/ 